\title{
Examining Some of the Challenges Students Face in Learning about Solubility and the Dissolution Process
}

\author{
Issa I Salame ${ }^{1 \star}$, Durica Nikolic ${ }^{1}$
}

${ }^{1}$ The City College of New York of the City University of New York, UNITED STATES

*Corresponding Author: isalame@ccny.cuny.edu

Citation: Salame, I. I., \& Nikolic, D. (2021). Examining some of the challenges students face in learning about solubility and the dissolution process. Interdisciplinary Journal of Environmental and Science Education, 17(3), e2237. https://doi.org/ 10.21601/ijese/9333

\section{ARTICLE INFO}

Received:

20 September 2020

Accepted:

13 November 2020

\section{ABSTRACT}

Developing conceptual understanding of solubility and dissolution and the relationship to molecular structure, ionic salts' charges, and enthalpy and entropy, play a significant role in the learning of chemistry. Dissolution and solubility are topics covered in general chemistry, quantitative analysis, biology, and organic chemistry. Alternative conceptions about some of the key chemistry principles can lead to students' failure in understanding and accepting some of the future concepts. This study aims to examine some of the challenges and alternate conceptions that students face when learning about solubility and its relationship to Lewis structures and the driving force behind dissolution. A survey that consisted of ionic and molecular solubility related problems, short answers, and Likert-Type questions was given to 200 students in order to analyze their understanding of solubility, dissolution, alternate conceptions they possess, challenges they face in learning about the topics, and its relationship to Lewis dot structures and ionic charges. Our data indicates that students struggle with solving solubility and dissolution process related problems and rely on memorization to approach these problems. For ionic compounds, there seems to be a dependency on memorization and rote-learning of solubility rules instead of development of conceptual understanding of charges of ions and their relationship to entropy and enthalpy in the dissolution process. For molecular compounds, it should be noted that students lack mastery of determining molecular shape and its relationship to function but do emphasize the roles of Lewis structure and polarity in solubility. Finally, students do not attribute the combined effects of enthalpy and entropy as the driving forces behind dissolution and show very fragmented and naïve understanding of the concept.

Keywords: chemistry, solubility, dissolution, rote-learning, lewis structures

\section{INTRODUCTION}

Learning chemistry is a cumulative process in which every share of information is accumulated based on the prior knowledge (Özmen, 2004). One of the definitions of misconception, alternative conception, is a wrong idea, concept, or opinion that is not based on scientific understanding (Luxford \& Bretz, 2014). Having established alternative conceptions of some fundamental concepts in general chemistry can have a significant effect on understanding some more intricate concepts that will show up in the future chemistry or any other chemistry related classes. There are five factors that contribute to the development of alternative conceptions in students' minds and those are: teachers, textbooks, students, contexts, and teaching methods (Setowati, Utomo, \& Ashadi, 2018). Once such an idea, notion, or opinion is developed it is not easy to remove it and establish a new, accurate one. This can actually have an essential impact on the students' success, comprehension and acceptance of some of the upcoming ideas and concepts that might appear in future classes. The presence of alternative conceptions in chemistry inhibits learning of other concepts since most chemistry concepts are related to one another (Nimmermark, Ohrstrom, Martensson, \& Davidowitz, 2016). It is significant to identify the kind of alternative conceptions students have in order to help them understand and apply a particular concept in the most productive way. 
There are numerous alternative conceptions that students develop throughout their education. The language used in these textbooks can give rise to the alternative conceptions that students have about different topics including those in chemistry (Pedrosa \& Diaz, 2000). Some of the alternative conceptions that students have in chemistry are related to ionic and covalent bonding. This all emerges from high school and general chemistry classes, when these basic concepts of chemistry were taught. Namely, it is presented by means of dichotomy, meaning that bonding can be classified as either covalent or ionic. This might seem convenient and easier to present chemical bonding at that level of chemistry. However, research shows that this can represent an obstruction with future studying about bonding (Luxford \& Bretz, 2014). Once, an alternative conception is developed, it is not easy to change it by using a traditional way of teaching (Onder \& Geban, 2006).

In their article, Ipek and co-authors (2010) suggests that teacher candidates should identify their alternative conceptions and this will cause a decrease in the level of alternative conceptions contracted in students' mind. In order for students to learn new concepts and develop an understanding, prior knowledge and information become key to their success (Dickmann, Opfermann, Dammann, Lang, \& Rumann, 2019). It is important that there is a productive communication among scientists and the community for the purposes of comprehending and accepting science and precollege education is a significant period of time for this acceptance to improve (Najmr, Chae, Greenberg, Bowman, Harkavy, \& Maeyer, 2018).

It is observed that students have issues understanding solubility and the factors that have an impact on the solubility of a molecule (Ipek, Kala, Yaman, \& Ayas, 2010). In one study, the author illustrates that at the students' early education in chemistry start to develop their alternative conceptions about solubility (Stojanovska, 2017). It is clear that students in their early educational period develop alternative conceptions, in this case it is solubility, that later on could have an effect on their understanding other concepts in chemistry, biology, or physics. So, a prior knowledge of a student can be either "useful foundational knowledge or can act as barriers to future learning" (Krause, 2013).

Moreover, students have problems with understanding the octet rule, polarity, shape, intermolecular forces, electrostatic interactions between atoms, and periodic trends (Luxford \& Bretz, 2014). This all can have an effect in their understanding of solubility and how the three dimensional structure of a molecule can play a role in solubility. Considering the importance of Lewis structures in relation to solubility and function, science education researcher studies whether students recognize the importance of these dot electron structures (Cooper et al., 2012). The study concluded in showing the student's ability to answer questions correctly, but now using the knowledge and skills required to do so. Furthermore, students have issues understanding, dipole-dipole forces and dispersion forces. Understanding this concept is crucial to understand how polar solvent is able to dissolve polar solute, and how nonpolar solvent has the ability to dissolve the nonpolar solute.

Chemistry is a conceptual subject founded on a numerous of abstract concepts. Chemical comprehension is taught at three levels; macroscopic, microscopic, and symbolical (Johnstone, 1993). Students have difficulties differentiating between the macroscopic and microscopic descriptions because the microscopic level is mistreated in teaching. Namely, the material is presented in such a way that from macroscopic level it is straight moved to symbolical level. Microscopic level is an important one since it contributes to the understanding the behavior of substances and their phenomena. Chemical formulas and names (symbolic) are used in metabolic charts to explain what is happening at the sub-microscopic level. Students need to be knowledgeable in all three levels to adequately understand metabolic pathways; however, this takes time because introducing all three levels together is not efficient and can easily lead to cognitive overload (Johnstone, 2000).

The reason alternative conceptions appear and increase over time is because the fundamental knowledge was miss-constructed in the mind of a student (Ipek et al., 2010). It seems that students confront challenges that are related to some of the fundamental concepts of chemistry (Onder \& Geban, 2006). "Students resist changing their views and explanations in conventional teaching or lecturing classrooms because the teacher-centered courses do not always cause conceptual change as they do not address the basic principle that knowledge is constructed in the mind of the learner" (Salame, Sarowar, Begum, \& Krauss, 2011). Also, lack of initial knowledge, prejudices, and using daily language in scientific issues are just some of the reasons that misconceptions establish in the mind of a student.

There are numerous alternative conceptions that are stated in chemistry textbooks. This is dangerous because it can cause a confusion to the teachers and then directly or indirectly to the students. Some of the alternative conceptions that are in the textbook are related to the electric dipole moment. Namely, most of the time as an example are taken diatomic molecules, where you have the bond symbols $A$ and $B$ and the arrow that is pointing 
from the positive towards the negative, usually where the positive sign is the tail of the arrow is crossed. "This is exactly the symbol modern general chemistry texts use. This convention is backwards and leads to misconceptions when applied to a more quantitative analysis of molecular interactions" (Hovick \& Poler, 2005).

Numerous textbooks are overwhelmed with a completely memorization-based approach to solubility (Blake, 2003). Blake criticizes educational system that forces students to memorize tables and that emphases algorithmic learning. One of those tables that most of the time students have to memorize or use is the one that shows the solubility guidelines; water-soluble and water insoluble-compounds. Instead of memorization, a conceptual understanding of topics should be emphasized (Blake, 2003).

Lewis structures are presented in the introductory chemistry courses and usually students have a difficult time to master to draw Lewis dot structures and understand simple bonding and molecular structure (VSEPR) (Nassiff \& Czerwinski, 2015). Understanding Lewis structures and how to properly draw them play an important role in understanding the structure and properties of a molecule. Lewis structures are considered as methods of communicating about molecular structures and play are significant role in reaction mechanisms and pathways (Finkenstaedt-Quinn et al., 2019). Only knowing how to draw Lewis dot structures without understanding their meaning can cause a misunderstanding of how the structure can have an effect on the activity of a molecule. Lewis structures, which forms the basis of symbolic language for chemistry communication, can help students to predict the molecular structure and its properties and facilitate the drawing of reaction mechanisms (Shultz \& Gere, 2015).

Lewis structure are the ones that can help students understand other essential concepts such as polarity, solubility, and intermolecular forces (Nassiff \& Czerwinski, 2015). There are formulas that can actually help students with step-by-step methods to draw Lewis structure in an efficient way. However, those formulas and steps do not contribute to students' understanding the concept behind the Lewis dot structures (Finkenstaedt-Quinn et al., 2019). Understanding valence electrons and the number of valence electrons is significant because that number is the one that represents the number of how many bonds an element is tending to make. Some of the alternative conceptions about Lewis structures include incomplete octet, too many bonds (Nassiff \& Czerwinski, 2015).

There are students who confront issues with understanding the connection between geometry and electrostatic properties of molecules. By using visual representations of molecules, the visual complexity can decrease, causing molecular relationships obvious, and therefore, provide benefits in pedagogy (Host et al., 2012). The reason for this issue might be because students have difficulties with interpreting the molecular shape and geometry which affects students' understanding of polarity and solubility (Host et al., 2012).

Solubility is a significant topic that is discussed in almost every chemistry and biology class. Solubility indicates the capacity of the solute to dissolve in a solvent. It is measured in terms of the maximum amount of solute dissolved in a solvent at equilibrium. The units can be presented in $(\mathrm{g} / \mathrm{L}),(\mathrm{g} / \mathrm{g})$, or $(\mathrm{mol} / \mathrm{L})$. In a case in which the solute dissolves, its own atoms cooperate with the solvent, become solvated, and are capable to diffuse selfsufficiently through the solution. Students do develop alternative conceptions that are related to solubility (Maass \& Krause, 2014). Solubility is also important when considering the design of a drug, since it is the one that influences the uptake, delivery, transport and the "bioactivity of a drug at the site of its actions" (Yan \& Gasteiger, 2002). So, as to get across biological membrane, a drug has to be water-soluble (Jorgensen \& Duffy, 2002). Understanding solubility and how the structure of the molecule can affect it, is important in understanding chemistry, as well as some biological concepts.

Namely, organic lithium compounds with branching alongside the main chain have a higher solubility in hydrocarbons (Kamienski \& Lewis, 1965). It is observed that the solubility of monosaccharaides, for instance, is determined by its geometry, atomic partial charges, as well as electronegativity (Jantschi, 2019). This is another example of how learning solubility in a chemistry class can be useful in understanding concepts in a biological course.

\section{Guiding Research Questions}

1. What are some of the challenges and alternative conceptions that students possess about solubility?

2 . Is there a relationship between these alternative conceptions and challenges and drawing Lewis structures and students' understanding of the driving force of dissolution?

3. What role does rote memorization play on learning about solubility and its impact on impeding students' learning?

\section{METHODS}

This research has an intention to discover and analyze some of the challenges that students face in learning about learning solubility and drawing Lewis dot structures in general chemistry class. In this study students from City 
Table 1. Question 1 from the survey handed out to students

Which of the following compounds are water-soluble? Circle all that apply.

\begin{tabular}{lll}
\hline $\mathrm{AgNO}_{3}$ & $\mathrm{Cs}_{3} \mathrm{PO}_{4}$ & $\mathrm{KClO}_{3}$ \\
$\mathrm{~K}_{2} \mathrm{CO}_{3}$ & $\mathrm{PbCl}_{2}$ & $\mathrm{MgBr}_{2}$ \\
$\mathrm{CaCrO}_{4}$ & $\mathrm{Ba}(\mathrm{OH})_{2}$ & $\mathrm{CaSO}_{4}$ \\
\hline
\end{tabular}

College of New York participated. Our method to answer the research questions was to collect data through questionnaire given out to The City College of New York students enrolled in general chemistry courses. Data was collected from students enrolled in general chemistry courses at the City College of New York a commuter, minority serving, urban, public university. The students represent a diverse number of majors ranging from science, engineering, liberal arts, and pre-health majors, to post baccalaureates. In order to analyze the challenges and alternative conception that students have related to solubility and dissolution, data was collected in the form of a survey. The survey was anonymous and it consisted of two solubility related problems, six short answer, and five Likert-type questions. The survey was given to two experts who agree that the questions adequately capture the investigation about solubility. The reliability coefficient was assessed to be 0.80 through the use of test-retest reliability method. Survey was administered and collected from 200 participants in accordance to the Internal Review Board (IRB). After collecting the survey, students' answers were categorized using a rubric and illustrated in a form of graphs and pie charts.

For the Likert-type questions, the answers were converted to numerical values and plotted as follows: (1)
Strongly Disagree, (2) Disagree, (3) Neutral, (4) Agree, and (5) Strongly Agree. We performed a single factor ANOVA on our Likert-type questions found $\mathrm{P}<.001$. P-value $<$ 0.05 , which is strong evidence against the null hypothesis and shows that there is stronger relationship between the variables. Additionally, the mean square for our data is 19.82 which is much larger than the mean square within the treatments which is 0.936 . The ratio between groupsmean square and within-groups mean square is 21.17566. This value is large enough to confidently reject the null hypothesis. For some of the open-ended questions the answers from respondents were coded based a rubric and were converted to numerical values similarly to the once in Likert-type questions. For some questions that involved lists, categories were created based on respondents answers and converted to percentages and plotted as a pie chart.

\section{RESULTS}

The data collected based on the question presented in Table 1 suggests that students struggle with answering questions related to ionic solubility and that the overwhelming majority of them could not get the answer to all of the parts of the question correctly. Based on our data, less than 10 percent of students answered the questions with no more than 1 incorrect answer. Also, about $85 \%$ of participating students had three or more mistakes. This could be attributed to the fact that they rely on memorization of solubility rules and rote learning which is not effective in learning and understanding.

Figure 1 represents a visual depiction with the percentages of strategies used in order to predict

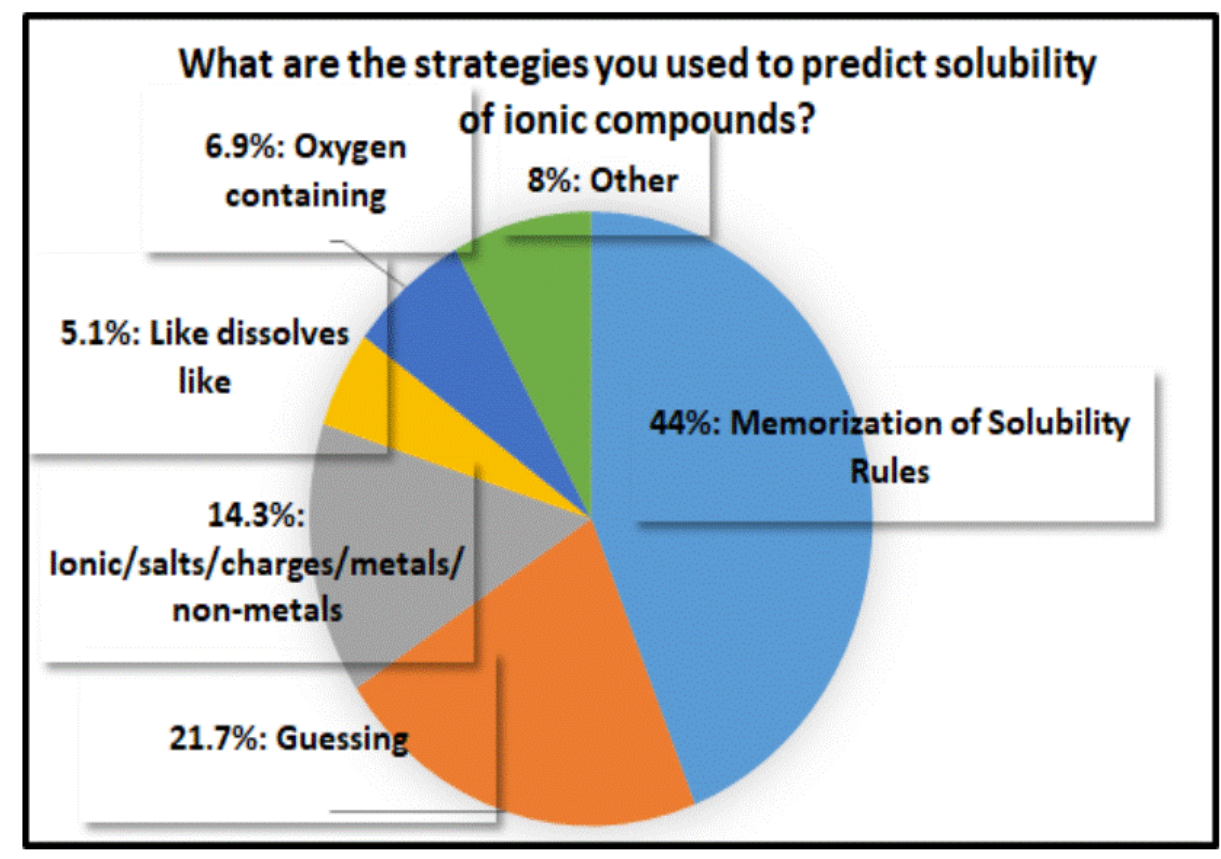

Figure 1. Pie chart showing strategies that students use to solve solubility problems of ionic compounds 
Table 2. Question 3 from the survey handed out to students

For each of the following compounds, state whether it is polar or nonpolar.

$$
\begin{aligned}
& \mathrm{SO}_{2} \\
& \mathrm{SO}_{3} \\
& \mathrm{CO}_{2}
\end{aligned}
$$

solubility of ionic compounds. According to this pie chart, we can realize that the largest percentage, $44 \%$, represents the students that stated that memorization of solubility rules plays an important role in their strategy for predicting solubility. Also, we can see that a significant number of students, $21.7 \%$, rely on guessing to solve solubility problems, which indicates that they do not have any rule-based strategy. Additionally, $14.3 \%$ stated that they predict solubility based on the ionic/ salts/charges/ metals/non-metals. It should be noted that $5.1 \%$ represent the students who said that their strategy is identifying the polarity and then use the rule that like dissolves like. While $6.9 \%$ of the students believe that oxygen presence plays a significant role in determining solubility.

When asked to determine whether molecular compound is polar or nonpolar, as shown in Table 2. For $\mathrm{SO}_{2}$, the data shows that $46 \%$ picked polar, and $54 \%$ of students choose nonpolar. Whereas for $\mathrm{CO}_{2}, 70 \%$ of students chose nonpolar as their answer. We can assume that the reason most of the students got $\mathrm{SO}_{2}$ incorrect is because they compared it to $\mathrm{CO}_{2}$, since they look similar. Most likely they did not consider the lone pairs on the
Sulfur that gives the $\mathrm{SO}_{2}$ a bent shape, and therefore makes it polar, but thought that has a linear shape just as $\mathrm{CO}_{2}$. The third molecular compound was $\mathrm{SO}_{3}$, and $55 \%$ of students labeled it as polar which is incorrect. Majority of the students labeled $\mathrm{SO}_{2}$ and $\mathrm{CO}_{2}$ as nonpolar, since they look similar, and that $\mathrm{SO}_{3}$ which looks unlike them is polar.

Figure 2 shows a visual depiction with the percentages of strategies used in order to predict solubility of molecular compounds. According to this pie chart, we can realize that the $42.6 \%$ of students stated that drawing Lewis dot structures helped them identify which molecular compound is polar and which one is nonpolar. A significant number, $13.0 \%$ of the students, say the electronegativity and dipole moment are important for determining the solubility of the molecular compounds. Also, based on this chart we can see that memorization and guessing plays an essential part of the strategies used: $15.4 \%$ stated that their strategy is guessing, while $7.4 \%$ claimed that memorization is their strategy.

Figure 3 illustrates the summary of the Likert-Type questions with a scale from 1 to 5,1 being strongly disagree and 5 being strongly agree. Based on this figure we can see that most of the students agreed with the statements that they struggled remembering all the different rules and exceptions for solubility, as well as, memorizing was a large part of learning solubility. A score of 3.79 on the Likert-type scale for students being unsure when performing solubility problems which suggests that it is due to the problematic nature of the topic. Additionally, students think that Solubility rules are a difficult part of

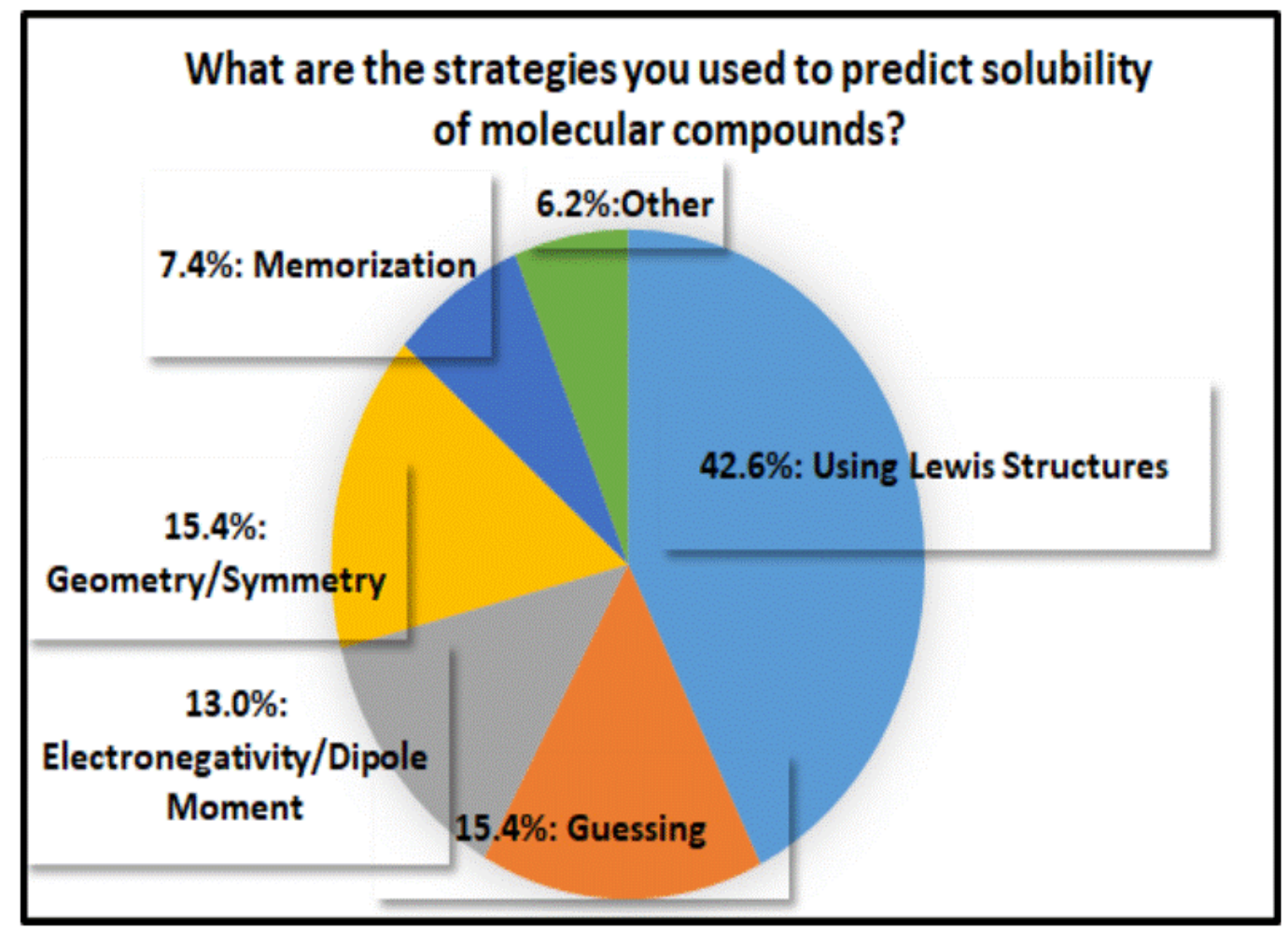

Figure 2. Pie chart showing strategies that students use to solve solubility problems of molecular compounds 


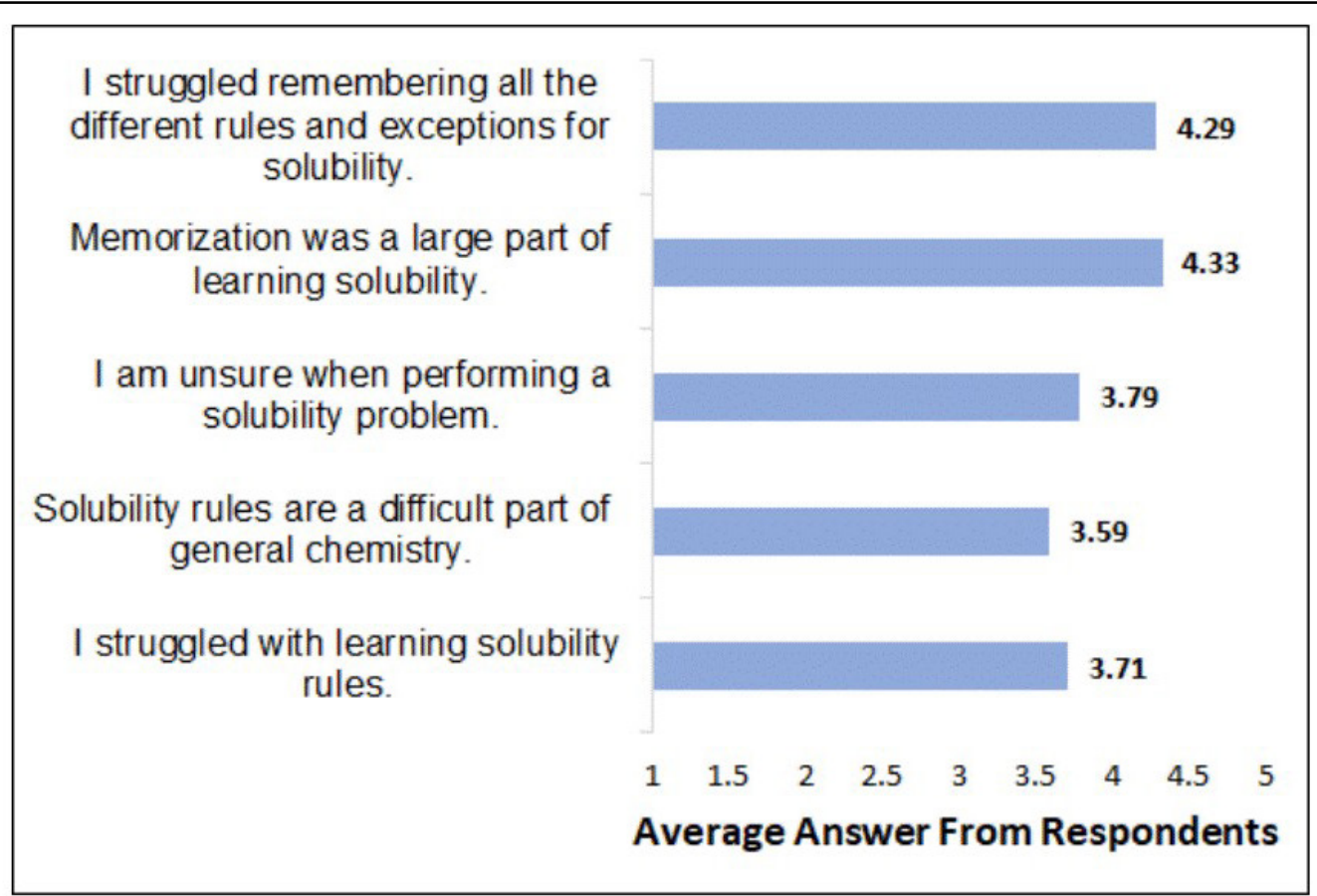

Figure 3. List of questions and averages of the Likert-Type questions

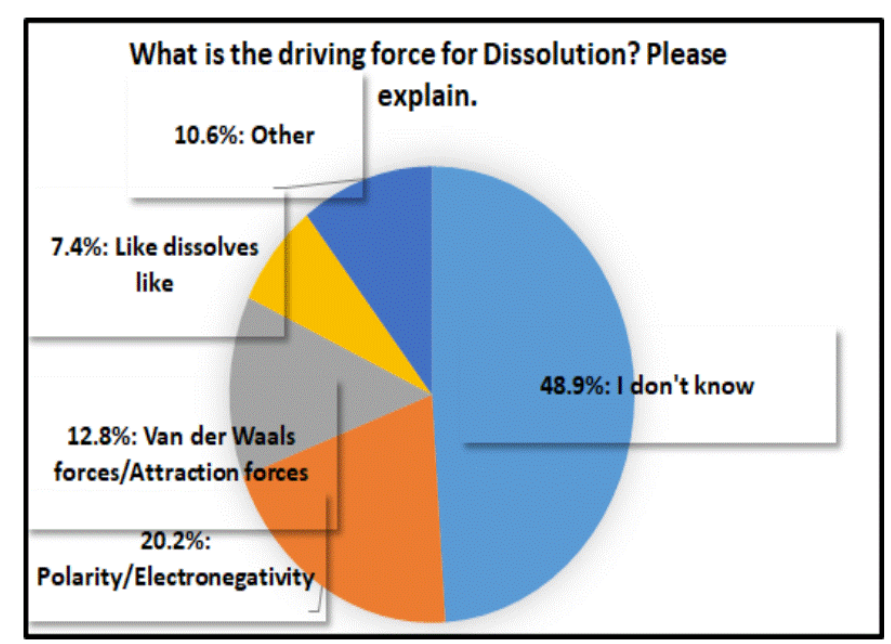

Figure 4. Pie chart showing students perceptions about the driving forces behind the dissolution process

general chemistry, and that they struggle with learning solubility rules.

Figure 4 represents a visual depiction with the percentages of students' explanation regarding driving forces behind the dissolution process. According to this pie chart, we can see that $48.9 \%$ of the students do not know how to answer this question. While $20.2 \%$ of them connected this question to the concepts of polarity and electronegativity. $7.4 \%$ used the "like dissolves Like" approach. While $12.8 \%$ stated that Van der Waals forces and attraction forces are the driving forces for dissolution.

Figure 5 illustrates a visual depiction with the percentages for the challenges that students face while learning solubility. According to this pie chart, we can observe that the majority, $72.6 \%$ stated that memorizing the solubility rules and exception is one of the biggest challenges. While other students, $2.6 \%$, think that not enough time was dedicated to the topic. Also, there is a small portion of the students, $2.6 \%$, that consider that everything is a challenge regarding learning solubility. Furthermore, the pie chart shows that $12.6 \%$ of students stated that they do not know the answer to the question and $3.3 \%$ of the students consider determining which compounds are polar/nonpolar as a challenge.

Figure 6 shows a visual depiction with the percentages of explanations how students approach solubility problems. Based to this pie chart, we can see that about $30.6 \%$ of the students use solubility rules and charts to solve solubility related problems. While the $36 \%$ of them stated that they memorize the rules. Also, there are students, $7.2 \%$, that are just guessing and there are $11.7 \%$ of who state that first determine if a compound is polar or 


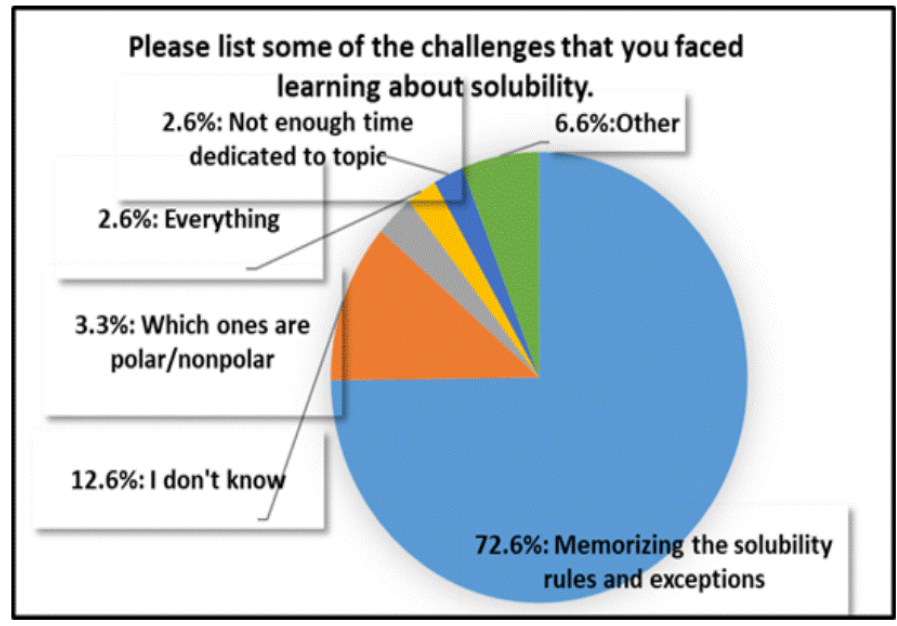

Figure 5. Pie chart showing list of challenges that students faced in learning about solubility

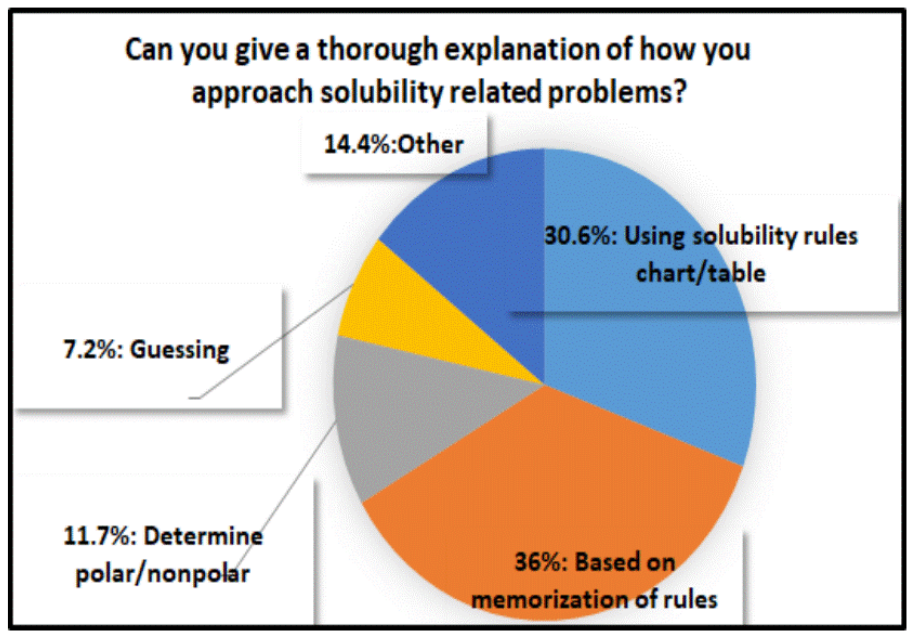

Figure 6. Pie chart showing list of approaches used to solve solubility problems

nonpolar.

\section{DISCUSSION}

Based on our research data, students have and hold onto alternative conceptions regarding solubility problems and that they are struggling with learning concepts related to solubility. Also, the data suggests that majority of the students rely on memorization of the solubility rules to solve problems and consider it as one of the challenges when learning solubility.

Students struggle determining the shape of chemical molecules and thus their polarity which could be the result of their struggles and alternative conceptions about Lewis structures. The ability to draw and manipulate Lewis structures is an important stepping stone for developing an understanding of the relationship between structure and property such as polarity (Ahmad \& Omar, 1992). Reliance on memorization rather than understanding when solving solubility problems impedes students meaningful learning and development of conceptual understanding. Students rely on memorizing a set of rules in drawing Lewis structures which does not necessarily translate to conceptual understanding and their ability to apply the rules become less efficient with more complex molecules (Nassiff \& Czerwinski, 2015).

Our data suggest that it is challenging for students to determine Lewis structure and use it to predict polarity and solubility. This is consistent with research published in this journal that argues that learning to draw Lewis structures is a cognitively complex challenge for students that requires assimilation of information that students have a weak knowledge of and the use of obscure rules; despite the importance of drawing and understanding Lewis structure it still poses a challenge for students to learn (Cooper et al., 2010).

Based on Figure 2, we can see that most of them knew that Lewis dot structures and Geometry/symmetry plays a significant role in determining polarity of a molecule, however, students did not apply that correctly. They either did not draw the Lewis dot structure correctly 
or they did not know how the geometry affects the polarity. This data is consistent with other research in the field that states that rote memorization of how to draw Lewis structures cannot help students understand their meaning (Finkenstaedt-Quinn et al., 2019). So, the reason students cannot spread their comprehension of molecular structures in some new concept is because the traditional method is still used to teach students how to draw Lewis dot structures.

Also, based on Figure 4, more time should be spent with the topic related to driving forces and the dissolution process, since almost half of the students had no idea how to answer that question. Traditionally, solubility is explained in terms of attractive forces between solvent and solute which leaves students with the alternative conception that solubility relies primarily on enthalpy instead of the combined contribution of enthalpy and entropy. Salts with anions and cations that have multiple charges are likely to be insoluble due to entropy role in the dissolution process, while the exceptions of this solubility rule are usually due to the large positive enthalpies of dissolution (Eisen et al., 2014). Students hold alternative conceptions about the driving force behind the dissolution and precipitation processes and their relationship to enthalpy and entropy (Ebenezer \& Fraser, 2001; Abell \& Bretz, 2019).

Figure 6 , also illustrates that students see chemistry and the solubility related problems as something that has to be memorized. As it is well established, not all ionic compounds are water soluble, and this forces students to memorize solubility rules to predict solubility of ionic compounds (Tro, 2011). So, memorization and holding onto their alternative conceptions are problems that students are facing in general chemistry classes.

The data supports the notion that memorization is not helping students to solve the solubility problems. Pedagogical researchers criticize the traditional practice and its efficiency is low, since it is based primarily on memorization and applying algorithms to solve problems (Dubova, 2014). Memorization represents an essential part when learning about solubility and precipitation reactions (Blake, 2003). Students admit that their strategy to solve solubility problems is memorization. Students perceptions of teaching and learning is just memorization (Schullery, 1976). A traditional way of teaching implies that the lecturer presents a lecture in a way that the student is forced to memorize the material without thinking. So, this method does not encourage or motivates students to think critically and attempt to solve the problems in a logical way. Additionally, students are not actively involved in the learning process.

The solubility table that students have to memorize, will stay in their memory for a short period of time due to their limited short-term memory and their ability to process only small chunks of information (Bunce, 2009). It will stay just long enough to pass the exam and then most of them will forget the majority of those rules. Remembering information about solubility rules and tables which is based on rote memorization is the lowest level of learning on Bloom's Taxonomy (Bloom, 1956). In a case in which a student does not comprehend a specific basic concept, there is a high probability that student will have a problem in understanding more complex concepts that will appear in some future classes (Setowati et al., 2018).

So, presenting molecules in three dimensions is significant since that will help students think about molecules in three dimensions and therefore be more precise when determining the molecular shape and geometry of a molecule. Presenting molecules in three dimensions should be very useful for teaching symmetry and point groups (Scalfani \& Vald, 2014), which provides valuable chemical information about structures (Yan \& Gasteiger, 2002). Picturing molecular characteristics is usually important in creating conceptual understanding in chemistry (Host et al., 2012). Having all this in mind, it could be concluded that more time should be dedicated to the concept of Lewis dot structures and their representations. There are a variety of approaches that instructors in order to help students in their better understanding the material of a particular course. Some of those approaches include, problem-based instruction, team learning, guided-inquiry learning, and case study (Schaber et al., 2010).

The abstract nature of the solubility and dissolution concepts are challenging for students to learn especially because they have to be able to make connections between the three levels of representations which are the macroscopic, microscopic and symbolic (Johnstone, 1993). Development of conceptual understanding of the processes taking place at the microscopic level in the dissolution process of ionic and covalent compounds has been found to be a challenge to the learners (Barke et al., 2009). Students who are able to visualize chemical processes at the microscopic level are more capable of constructing a conceptual understanding of chemistry content and knowledge (White, 1988). One of the challenges that face students in learning about solubility is that they extend their understanding of matter at the macroscopic level to the microscopic level (Ebenezer \& Erickson, 1996).

Researchers suggest that we can improve students' learning and conceptual understanding by connecting microscopic nature of reactions to symbolic nature of 
chemical reactions and the macroscopic level, and by addressing students' alternative conceptions (Kelly et al., 2010). When students develop their conceptual understandings of solubility at the microscopic level they can learn the topic more in depth (Bruck et al., 2010). Students hold onto their alternative conceptions and rely on rote learning of even some of the most basic chemistry concepts (Bodner, 1991). Conceptual understanding of chemical knowledge can be achieved when the three levels, macroscopic, microscopic, and symbolic, are taught with the interplay between the three levels (Harrison \& Treagust, 2000).

\section{CONCLUSIONS}

The data collected from this research suggests that students face challenges in learning about solubility and dissolution and hold onto their alternative conceptions after traditional instruction. Students list memorization of the solubility rules, their exceptions, and the determination of polarity as the major impedances and challenges they face in learning about solubility.

Our data suggests that for ionic compounds students rely on memorization and rote-learning of solubility rules instead of developing their conceptual understanding of charges of ions and their relationship to entropy and enthalpy in the dissolution process. For molecular compounds, students place emphasis on the role of Lewis structures, electronegativity, and polarity for determining solubility. It should be noted that they struggled in identifying polar molecules due to lack of mastery of Lewis structures and molecular shape.

Furthermore, students' understanding of the dissolution process presents an obstacle to their learning of solubility and dissolution. Students do not attribute enthalpy and entropy as the driving forces behind dissolution and show very fragmented and naïve understanding of the concept by relying on phrases such as "like-dissolves-like". This might be a catchy phrase in chemistry and it leads students to develop alternative conceptions and hold onto their own. Additionally, they refer to attractive forces as the reason for dissolution which is consistent with some of the General Chemistry textbooks explanation that lacks any mention of entropy. The solution process is often covered in the chapter of "Solutions" which usually is a few chapters before entropy and free energy are presented.

More research is needed in the field of alternative conceptions in chemistry, especially in the area that is related to solubility, dissolution, polarity, and ionic charges. It is important to detect the type of alternative conceptions students developed in order to help them comprehend and use a specific concept in the most fruitful way. Learning and teaching of solubility and dissolution can be improved by connecting the microscopic nature of the process to the symbolic and macroscopic level. Understanding students' challenges and alternative conceptions allow instructors to incorporate active learning and conceptual change to address them. There is a need to change from the traditional method of teachercentered passive-learners to student-centered activelearners to address alternative conceptions and improve understanding.

Allowing students to work collaboratively in an inquiry-based activity or be involved in another active learning process that addresses conceptual changes and facilitates the development of conceptual understanding and collecting data using a pre-post-survey would provide valuable information and provide to be a reasonable future study.

\section{REFERENCES}

Abell, T. N., \& Bretz, S. L. (2019). Macroscopic observations of dissolving, insolubility, and precipitation: General chemistry and physical chemistry students' ideas about entropy changes and spontaneity. Journal of Chemical Education, 96(3), 469-478. https://doi.org/10.1021/acs. jchemed.8b01007

Ahmad, W.-Y., \& Omar, S. (1992). Drawing Lewis structures: A step-by-step approach. Journal of Chemical Education, 69, 791-792. https://doi.org/10.1021/ed069p791

Barke, H.-D., Hazari, A. \& Yitbarek, S. (2009). Misconceptions in chemistry: Addressing perceptions in chemical education. Berlin: Springer.

Blake, B. (2003). Solubility rules: Three suggestions for improved understanding. Journal of Chemical Education, 80, 1348-1350. https://doi.org/10.1021/ed080p1348

Bloom, B. S., Ed. (1956). Taxonomy of educational objectives: The classification of educational goals, Handbook 1: Cognitive Domain; David McKay: New York.

Bodner, G. M. (1991). I have found you an argument: The conceptual knowledge of beginning chemistry graduate students. Journal of Chemical Education, 68(5), 385-388. https://doi.org/10.1021/ed068p385

Bruck, L. B., Bruck, A. D. \& Phelps, A. J. (2010). "Gone" into solution: Assessing the effect of hands-on activity on students' comprehension of solubility. Journal of Chemical Education, 87(1), 107-112. https://doi:10.1021/ed800016f

Bunce, D. (2009). Teaching is more than lecturing and learning is more than memorizing. Journal of Chemical Education, 86, 674-680. https://doi.org/10.1021/ed086p674

Cooper, M. M., Grove, N., Underwood, S. M. \& Klymkowsky, M. W. (2010). Lost in Lewis structures: An investigation of student difficulties in developing representational competence. Journal of Chemical Education, 87(8), 869-874. https://doi. org/10.1021/ed900004y

Cooper, M. M., Underwood, S. M., \& Hilley, C. Z. (2012). Development and validation of the implicit information from Lewis Structures instrument (IILSI): Do students connect structures with properties? Chemistry Education Research and Practice, 13, 195-200. https://doi.org/10.1039/ C2RP00010E 
Dickmann, T., Opfermann, M., Dammann, E., Lang, M., \& Rumann, S. (2019). What you see is what you learn? The role of visual model comprehension for academic success in chemistry. Chemistry Education Research and Practice, 20(4), 804-820. https://doi.org/10.1039/C9RP00016J

Dubova, M.V. (2014). Problems of primary education today. Russian Education and Society, 56, 3-14. https://doi. org/10.2753/RES1060-9393560501

Ebenezer, J., \& Erickson, G. (1996). Chemistry students' conceptions of solubility: A phenomenography. Science Education, 80(2), 181-201. https://doi.org/10.1002/ (SICl)1098-237X

Ebenezer, J. V., \& Fraser, D. M. (2001). First year chemical engineering students' conceptions of energy in solution processes: Phenomenographic categories for common knowledge construction. Science Education, 85(5), 509-535. https://doi.org/10.1002/sce.1021

Eisen, L., Marano, N., \& Glazier, S. (2014). Activity-based approach for teaching aqueous solubility, energy, and entropy. Journal of Chemical Education, 91, 484-491. https:// doi.org/10.1021/ed4005563

Finkenstaedt-Quinn, S.A., Snyder-White, E.P., Connor, M.C., Gere, A.R., \& Shultz, G.V. (2019). Characterizing peer review comments and revision from a writing to -learn assignment focused on Lewis structures. Journal of Chemical Education, 96, 227-237. https://doi.org/10.1021/acs.jchemed.8b00711

Harrison, A. G., \& Treagust, D. F. (2000). Learning about atoms, molecules, and chemical bonds: A case study of multiplemodel use in grade 11 chemistry. Science Education, 84, 352381. https://doi.org/10.1002/(SICI)1098-237X

Host, G.E., Schonborn, K.J., \& Palmerius, K.E.L. (2012). Students' use of three different visual representations to interpret whether molecules are polar or nonpolar. Journal of Chemical Education, 89, 1499-1505. https://doi. org/10.1021/ed2001895

Hovick, J.W., \& Poler, J.C. (2005). Misconceptions in sign conventions: Flipping the electric dipole moment. Journal of Chemical Education, 82, 889. https://doi.org/10.1021/ ed082p889

Ipek, H., Kala, N., Yaman, F., \& Ayas, A. (2010). Using POE strategy to investigate student teachers' understanding about the effect of substance type on solubility. Procedia Social and Behavioral Sciences, 2, 648-653. https://DOl:10.1016/j. sbspro.2010.03.078

Jantschi, L. (2019). Structure-property relationships for solubility of monosaccharides. Applied Water Science, 9, 1-11. https://doi.org/10.1007/s13201-019-0912-1

Johnstone, A. H. (1993). The development of chemistry teaching: A changing response to changing demand. Journal of Chemical Education, 70(9), 701-705. https://doi. org/10.1021/ed070p701

Johnstone, A. H. (2000). Teaching of chemistry - logical or psychological? Chemistry Education Research and Practice, 1(1), 9-15. https://doi.org/10.1039/A9RP90001B

Jorgensen, W.L., \& Duffy, E.M. (2002). Prediction of drug solubility from structure. Advanced Drug Delivery Reviews, 54, 355-366. https://doi:10.1016/s0169-409x(02)00008-x

Kamienski, C.W., \& Lewis, D. H. (1965). Relationship between structure and solubility of organic lithium compounds. Analytical Chemistry, 33, 468-474. https://doi.org/10.1021/ jo01021a051

Kelly, R. M., Barrera, J. H., \& Mohamed, S. C. (2010). An analysis of undergraduate general chemistry students' misconceptions of the submicroscopic level of precipitation reactions. Journal of Chemical Education, 87(1), 113-118. https://doi.org/10.1021/ed800011a

Krause, J.S. (2013). The effect of visually-based intervention on students' misconceptions related to solutions, solubility, and saturation in a core materials course. American Society for Engineering Education, 12. 540.1-12.540.12.

Luxford, C. J., \& Bretz, S. L. (2014). Development of the bonding representations inventory to identify student misconceptions about covalent and ionic bonding representation. Journal of Chemical Education, 91, 312-320. https://doi.org/10.1021/ed400700q

Maass, S., \& Krause, S. J. (2014). The effect of incorporation YouTube videos into an intervention addressing students' misconceptions related to solutions, solubility, and saturation. Proceedings of the ASEE Annual Conference \& Exposition, 1-17.

Najmr, S., Chae, J., Greenberg, M.L., Bowman, C., Harkavy, I., \& Maeyer, J.R. (2018), A service-learning chemistry course as a model to improve undergraduate scientific communication skills. Journal of Chemical Education, 95, 528-534. https:// doi.org/10.1021/acs.jchemed.7b00679

Nassiff, P., \& Czerwinski, W. A. (2015). Teaching beginning chemistry students simple Lewis dot structures. Journal of Chemical Education, 92(8), 1409-1411. https://doi. org/10.1021/ed5007162

Nimmermark, A., Ohrstrom, L., Martensson, J., \& Davidowitz, B. (2016). Teaching of chemical bonding: A study of Swedish and South African students' conceptions of bonding. Chemistry Education Research and Practice, 17, 985-1005. https://doi.org/10.1039/C6RP00106H

Onder, I., \& Geban, O. (2006). The effect of conceptual change texts oriented instruction on students' understanding of the solubility equilibrium concept. H.U. Journal of Education, 30, 166-173.

Özmen, H. (2004). Some student misconceptions in chemistry: A literature review of chemical bonding. Journal of Science Education and Technology, 13(2), 147-159. https:// DOI:10.1023/B:JOST.0000031255.92943.6d

Pedrosa, M. A., \& Dias, M. H. (2000). Chemistry textbook approaches to chemical equilibrium and student alternative conceptions. Chemistry Education Research and Practice, 1(2), 227-236. https://doi.org/10.1039/A9RP90024A

Salame, I. I., Sarowar, S., Begum, S., \& Krauss, D. A. (2011). Students' alternative conceptions about atomic properties and the periodic table. Chemical Educator, 16, 190-194.

Scalfani, V.F., \& Vald, T.P. (2014). 3D printed molecules and extended solid models for teaching symmetry and point groups. Journal of Chemical Education, 91, 1174-1180. https://doi.org/10.1021/ed400887t

Schaber, P.M., Dinan, F.J., Phillips, M., \& Larson, R. (2010). Juicing the juice: A laboratory-based case study for an instrumental analytical chemistry course. Journal of Chemical Education, 88, 496-498. https://doi.org/10.1021/ed100863d

Schullery, S. E. (1976). Formal operational: Where is it really needed? Journal of Chemical Education, 56(11),768. https:// doi.org/10.1021/ed056p768.1

Setowati, H., Utomo, S.B., \& Ashadi., A. (2018). Students' misconceptions on solubility Equilibrium. Journal of Physics, 1022, 1-5. https://DOI:10.1088/1742-6596/1022/1/012035

Shultz, G.V., \& Gere, A.R. (2015). Writing-to-learn the nature of science in the context of the Lewis dot structure model. Journal of Chemical Education, 92, 1325-1329. https://doi. 
org/10.1021/acs.jchemed.5b00064

Stojanovska, M. (2017). Conceptual understanding of solubility concepts among first-grade high school students, contributions. Section of Natural Mathematical and Biotechnological Science, MASA, 38, 109-115. https:// DOI:10.20903/csnmbs.masa.2017.38.1.107

Tro, N. J. (2011). Solutions. In Chemistry A Molecular Approach; Prentice Hall: Upper Saddle River, NJ, pp 512-527.

White, R. T. (1988). Learning science. Basil Blackwell Ltd., Oxford.

Yan, A., \& Gasteiger, J. (2002). Prediction of aqueous solubility of organic compounds based on a 3D structure representation. Journal of Chemical Information and Computer Science, 43, 429-434. https://doi.org/10.1021/ci025590u 